\title{
RESEARCHING AND EVALUATING DIGITAL STORYTELLING AS A DISTANCE EDUCATION TOOL IN PHYSICS INSTRUCTION: AN APPLICATION WITH PRE-SERVICE PHYSICS TEACHERS
}

\author{
Nihat KOTLUK \\ Faculty of Education, \\ Yuzuncu Yil University, Van, Turkey \\ Assoc. Prof. Dr. Serhat KOCAKAYA \\ Faculty of Education, \\ Yuzuncu Yil University, Van, Turkey
}

\begin{abstract}
Advances in information and communication technology in $21^{\text {st }}$ century have led to changes in education trends and today new concepts such as computer, multimedia, audio, video, animation and internet have become an indispensable part of life. The storytelling is the one of approach which is allowed to using technology in educational field. The aim of this study is to define the use of digital storytelling in physics instruction as a distance education tool. In this respect, the literature related to digital storytelling was analyzed and for applying it in practice, 13 pre-service teachers from department of physic education were trained on digital storytelling for 6 weeks in spring term of 20132014 academic year. Following the process of instruction, pre-service teachers created and shared digital stories in YouTube and evaluated all of them. Furthermore, opinions of the pre-service teachers were asked on digital story telling As a result of the analysing the DST videos and opinions of pre-service teacher, it is expected that using digital storytelling as distance education tool will be efficacious.
\end{abstract}

Keywords: Digital storytelling, Physics Instruction, Distance Education, Internet-based Learning.

\section{INTRODUCTION}

In $21^{\text {st }}$ century, new concepts and technological means such as computers, internet, multimedia, audio, video and animation have attained place in education and instruction (Alakoc, 2003). Today, by means of enhancement in technology and internet tools, internet access could be available from everywhere, even with cell phones. As individuals get access to internet independent from space and time, the use of internet is increasing (Karagulle and Cayci, 2014) and individuals get information whenever and wherever it is needed. These advances in information communication technology causes information to emerge in various forms like audio, video, animation and combination. This, hence, leads to changes in education and instruction environments.

In facing the needs of knowledge period in which we live, requirements expected from the learner in educational activities undergo a change as well. Presently, the learner is anticipated not only to perform media and technology literacy but also to integrate technology, one of necessities of modern education, into education and instruction setting (Gunduz and Odabasi, 2004). Since today's individuals have technological 
opportunities like cell phone, television, video, internet and computer, any information concerning to a particular subject needs to be set up and to be enriched by technology.

Given the circumstance that people use technologic means such as computer, internet, and smart phones every day, it is vital to note that individuals (academicians, teachers and experts etc.)who are responsible for teaching in education and instruction environment should both resolve information in various forms of materials like video, audio, text, graphs and images and serve knowledge by combining and constructing to the learners and those who are dropout (Reiner, 2009).

Considering today's technological means as well as opportunities that individuals have, it is crystal clear that education and instruction are not any more just activities carried out in classroom environment. Whether individuals are in formal or non-formal education, even in distance learning, they can easily attain information anywhere and anytime they want. Hence, there is a need for new methods in education that enable individuals to construct the knowledge in combinations, to share it online and to make it accessible with ease. In this regard, digital storytelling appears to be an appropriate and effective method.

\section{DIGITAL STORYTELLING}

There have been many definitions about digital storytelling in related literature. Porter (2004) defined storytelling as combining authentic stories with image, music, graphs and voice-over while Dupain and Magure (2005) described it as creating a story by integrating multimedia elements such as visuals, audio, video and animation as well as Chung (2007) highlighted it as a harmonious multimedia presentation composed of digital components such as text, visuals, video and audio. However, digital storytelling are overall considered as generating a story about a subject by using multimedia tools and software and sharing this story in multimedia environment (Nguyen, 2011; Robin, 2008). Nearly all digital stories are originated via combining components (text, voice-over, video, music, and visuals) with an authentic story on a particular subject.

Digital stories, altogether, are short videos created by integrating image, video, background music and audible or written narration via some basic hardware and software (Microsoft Photo Story, Windows Movie Maker, Wevideo, Web 2.0 etc.) with authentic story (Wang and Zhan, 2010). Nevertheless, digital storytelling is not just a plain power point presentation (Dreon, Kerper, and Landis, 2011). Robin and Pierson (2005) noted that digital storytelling is the activity of producing meaningful stories that reflect individuals' imagination. Digital stories can have aim of informative, instructive and personal narration (Robin, 2008). Digital stories can rise up in different types ranging from personal narratives or instructional stories to narratives that recount historical events and in many different fields ranging from social science to science (Coutinho, 2010). Banaszewski (2005) pointed out that educational technologies have progressively taken place in education and instruction environment, accordingly, digital story have become widespread in classroom setting and in various fields of study as stated by many academicians, researchers and educators.

Digital storytelling has improved since educators started to use various kinds of digital narrating in 1990s. Digital stories enable people to create and share their own stories by using digital technology and media, so digital technology and especially social media, today, give teachers and students the opportunity to not only publish their own stories but also view and evaluate other stories (Garrety, 2008). Digital storytelling has, ever since 1990s, been used in many fields ranging from social sciences and language to science and literacy; moreover, it is being used in a number of different fields.

The considerable attention given to digital storytelling is credited to its having multiple viewpoints (Garcia and Rossiter, 2010). Digital storytelling serves as a popular pedagogical tool used for students from all ages and educational background as well as 
ethnicity (Garcia and Rossiter, 2010). What is more, the effect of digital stories have increased as it reaches to millions of people via internet (Standley, 2003).

\section{Types of Digital Stories}

It is highlighted in the related literature that there are many different types of digital stories used for various purposes. Robin (2008) who is one foremost figure concerning digital stories categorized these types into three major groups. These are:

1. Digital Stories That Instruct: Purpose of this type of digital stories is to teach certain issues or subjects to the viewers. Instructors can use this type for teaching subject from fields such as science, mathematics, history and social science (Robin, 2008). Kahraman (2013) has pointed out that the use of digital stories in physics instruction has become effective in students' achievement.

2. Personal Narratives: One of the reasons for using this type of digital stories is to share an account of experience, autobiography, memory or events that make up one's life.

3. Digital Stories That Recount Historical Events: The reason for producing this type is to examine historical events and convey the event with a different point of view. Historic photos and speeches are especially employed in these digital stories. Using historic images, newspaper headlines, speeches and other materials about historical events, students can create an authentic story that may reflect different perspective (Robin, 2008).

\section{Process of Producing Digital Story}

The process of creating a digital story is mainly described in six steps (Jakes and Brennan, 2005). These are:

1. Writing: In this step, the author or creator begins with finding a subject for the story. A draft of script is developed, and then it is discussed and reviewed by others. Finally, the draft of script is modified and completed in accordance with comments and evaluations.

2. Script: The script is brought to a whole after completion of narrative. This script also defines the multimedia elements to be used in the story and how these multimedia components will be used; in this respect, script is regarded as the basis of digital story.

3. Storyboarding: Storyboarding is the plan of sequencing scenes, transitions and the effects. The aim of storyboard process is to visualize how a movie or digital story will work. Storyboard is used for organizing and planning harmony of music, image, audio and video (Lambert, 2010).

4. Locating Multimedia: This step can be defined in two phases; (a) on completing storyboarding, the author searches for multimedia components (visuals, music, audio, photos, graphs etc.) to be used for sketching and enhancing the script by means of making use of sources online, in print or taking pictures. The components obtained from various sources are saved as files to a computer or USB flash driver. (b) Afterwards, it comes to record voice-over. It should be emphatic and emotional (Kajder and Swenson, 2004). Recording voice-over can be conducted via computers equipped with speakers and microphones, smart phones, tape or digital recorders. During the record, it is essential that the environment should be silent and record be rehearsed once or twice to make it effective.

5. Creating Digital Story: In this step, digital story is produced by means of various software. All the components such as text, voice-over, visuals, graphs, animations, photos and music are combined. In order to create digital story, Microsoft Photo Story, Windows Movie Maker, Wevideo (www.wevideo.com) or Web 2.0 can be employed. All the components are associated with each other to organize a harmonious flow of video. Once the components are assembled, the final video is produced, that is, rendering and then it is saved on computer. 
6. Sharing Digital Story: As for this step, which is the most critical one, digital story is shared with individuals in classroom or social media such as YouTube, facebook, twitter etc. Finally, the process of creating digital story is completed after taking comments and evaluations from viewers.

In process of producing digital story, author picks and explores an issue or subject. Using the information obtained from the search, author writes a text and, based on this text, creates an authentic script. Then a short video is produced by combining visuals, graphs, audio, text, animation and music with the script, namely authentic story. Finally, this combination is transformed into a short video that can be viewed in digital environment (Robin, 2008). Digital stories are viewed and evaluated by individuals. In the upshot of this process, certain skills such as writing, arranging, technology literacy, presenting, problem-solving, evaluating and collaboration (Robin, 2006).

However, in order to produce effective digital stories, it is essential to consider seven elements (Robin, 2006; Lambert, 2010). They are:

1. Point of View: Main perspective that author reflects.

2. A Dramatic Question: A question that attracts attention and will be answered at the end of story.

3. Emotional Content: Story or content that will inflect viewers.

4. Gift of Your Voice: Narration that helps viewers to personalize the story.

5. Power of Soundtrack: Music or other sounds that support and embellish the story.

6. Economy: Employing enough content without unnecessary components.

7. Pacing: The rhythm of the story and how slowly or quickly it paces.

\section{Digital Storytelling and Physics Instruction}

Digital storytelling is employed with the purpose of teaching course content inside or outside classroom environment, allowing students to be active learners, creating communities, fostering collaboration as well as providing students with technology literacy (Karakoyun, 2014). Digital stories in teaching-instruction environment are implemented concerning such fields as society, culture and language (Banaszewski, 2005; Yang and Wu, 2012; Demirer, 2013). Notwithstanding, studies on the use of digital stories in physics instruction seem to be scarce in the related literature. With respect to the process of its emergence, in Turkey it appears that digital storytelling is not adequately recognized and implemented in physics instruction apart from a few studies (Kahraman, 2013). Moreover, in Turkey it is considered that thanks to methods such as digital storytelling that can provide individuals with opportunity to engage in physics, individuals could use multimedia tools more effectively and efficiently and benefit from mobile phones, internet and computer inside and outside teaching-instruction environment, even in daily life.

Digital stories related to physics subjects can be supplied to individuals without any limitation of place and time with the help of sharing via internet. Therefore, viewing digital stories, learners could attain knowledge about the subject they are searching. As a result, digital stories, digital stories could be used as a distance education tool that is based on internet.

\section{Internet-Based Distance Education}

The sharp increase in the use of internet and methods that tend to seek using of internet led to take place in teaching-instruction environment. Distance learning is an education model in which not only instruction content are conveyed but also interaction is carried out by means of communication technologies without any restriction in space and time between the learner and educator. Highlighted benefits of internet-based distance learning as below;

> Students can compensate for the subject that they could not keep up with if it is supplied as a support to formal education. 
$>$ Student can review subjects in course that are difficult to understand.

$>$ It can relieve problems resulting from lack of time.

$>$ It allows students to learn practice, application and simulations of the subject that are ignored in course, hence could not be recognized.

$>$ It can serve various solutions to problems and subjects that students have difficulty in acknowledging and practicing.

$>$ It supports the learning by offering more visuals about subjects.

$>$ It allows individuals, who aim to work rather than attending courses, to master a branch by means of modern technological tools.

\section{Importance of the Study}

In addition to benefits mentioned above, internet-based distance education could provide individuals, who dropped out of school because of lack of means and facilities, with opportunity of distance learning. In fact, regarding the aspects of distance education and life-long learning, making digital stories about physics subjects available, sharing them online, allowing students to explore digital stories about physics subjects that they are interested anytime and anywhere they feel like are of considerable importance. However, in the related literature, there is hardly a study that has been implemented for these purposes; hence, the need to carry out this study has emerged.

\section{MATERIAL AND METHOD}

\section{Purpose of the research}

The purpose of this study is to explore and discuss the usability of 'digital storytelling' as an online distance education tool in physics instruction. The main questions of the study were the following:

1. How do students perceive the impact of the using the Digital Storytelling on their learning of Physics?

2. Can we use The Digital Storytelling as a distance education tool in physics instruction? research questions was investigated and examined.

\section{Method}

Qualitative research method was used in this study. In the selection of the study group (13 volunteered), the purposeful sampling was used within the framework of the research. The data in this study were collected using interviews with 13 participant and document analysis. which is the analysis of the documents related to the topic focused on. In conducting document analysis, the borders of the topic studied should be determined clearly and the documents suitable to the nature of the topic should be selected (Yildirim and Simsek, 2011). In this study information obtained from books, studies, thesis, and internet sources about digital storytelling were reviewed and analysed. After digital stories about 'modern physics' subject were produced and shared on internet by pre-service physics teachers' view were gathered.

\section{Participants}

Participants of this study consist of $\mathbf{1 3}$ pre-service physics teachers registered to Physics Teacher Education Department of Education Faculty of Yuzuncu Yil University in spring term of 2013-2014 academic years.

\section{Research Procedures}

The duration of the study with 13 pre-service physics teachers was 6 weeks between April and May 2014. In the process of digital storytelling, pre-service physics teachers come up with an idea and they research, explore and learn about this idea, afterwards they write a script using the information gathered and create an authentic story. After gathering images, audio and graphics students blend their own story with these multimedia elements and finally create a short video that can be viewed in web or computer environment. Teacher-produced digital stories were viewed and evaluated by pre-service teachers. The outline of the application is shown in Table 1. 
Table 1

The outline of application with group

1.week process

Review Modern

Physics Unit and choose an interesting topic

3.week Arranging Scripts

4.week

5.week

6.week
Watch digital stories uploaded in Web Environments
Introduce DST procedures, Show the self-made digital story

Explain reasons for choosing the issues

Discussion of the Scripts In Groups Sharing Views on Script-
Images Harmony

Installing Background Music and students' Audio to Video

Share reflections and comments for each Video by the students
Introduce Windows Movie Maker

Content Scanning Related to Selected Issues

Scan for images

Search for Background Music

Upload 3-5 minute Digital Story to the Web Environment

Provide Feedback by the owners to the criticism of the videos and Making Corrections

\section{Data Collection Tools}

Interview. The interview items were developed by the researchers. Five items in the interview aimed at exploring students' perceptions of their learning and aimed to exploring digital storytelling as a distance education tool. The questions of the interview were the following:

1. Are you enjoy using the Digital Storytelling for Distance Education activities?

2. Do you think the use of Digital Storytelling on YouTube helped your learning?

3. Do you think the Digital Storytelling served as a learning aid?

4. Do you think using the Digital Storytelling as a distance education tool will be efficacious?

5. Do you think Digital Storytelling allowed you more creativity in designing projects and assignments?

Document Analysis

Information obtained from books, studies, thesis, and internet sources about digital storytelling were reviewed and analysed.

\section{RESULTS}

After six-week application, each pre-service teacher created an authentic digital story. A channel named as 'DST-YYU-FİŻK-2014' was created and subscribing this channel, teachers uploaded their own digital stories and then they evaluated one another's stories. Meanwhile it was also announced to other students, academicians and teachers to view and evaluate student-produced videos from the linkhttps://www.youtube.com/channel/UCC2nHVHF1RLO2zpS6uOm6Mg Subsequent to evaluation, some pre-service teachers are demanded to prepare one more digital story so 
17 digital stories were published on total. Besides, pre-service teachers were allowed to share digital stories in social media such as Facebook, Twitter and so on. Subjects, spans and links of digital stories are given below:

1. Photoelectric Effect: https://www.youtube.com/watch?v=j8SYTYIc3XQ

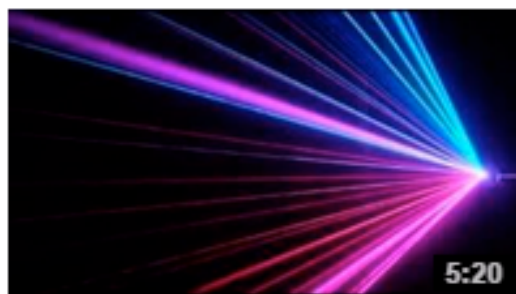

2. General Relativity: https://www.youtube.com/watch?v=PIEmTnb90IE

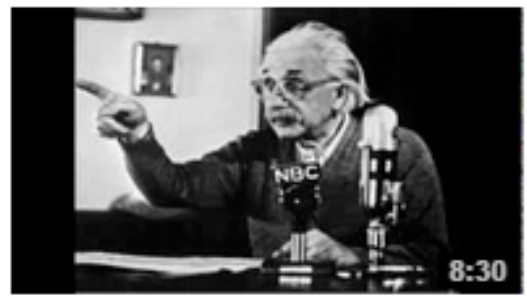

3. X-Ray: https://www.youtube.com/watch?v=NkcbCgXAk10

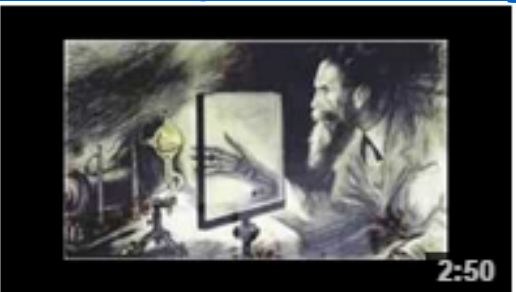

4. Radioactivity: https://www.youtube.com/watch?v=f8-CBbge1Mw

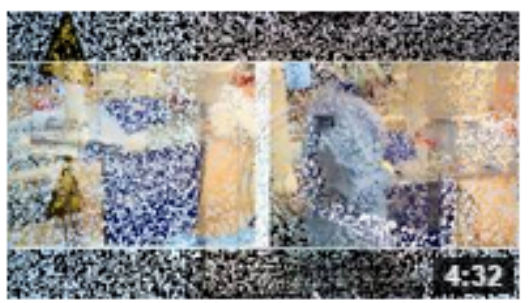

5. Michelson and Morley Experiment:

https: //www.youtube.com/watch?v=wIPKOwSqga4

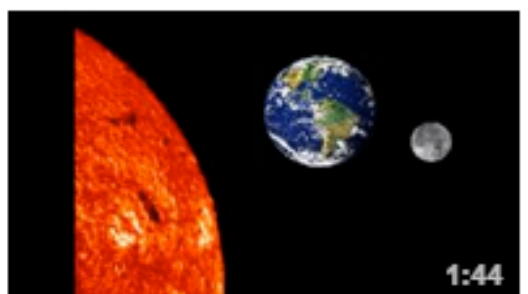

6. Franck-Hertz Experiment: https://www.youtube.com/watch?v=sQ6BwpAjt6I

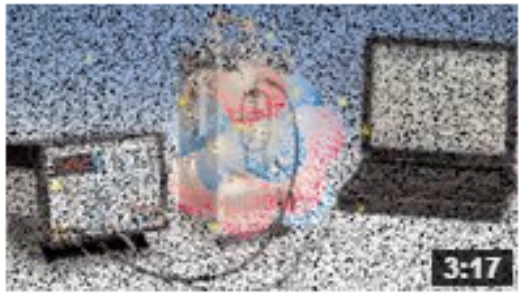

7. Black Hole: https://www.youtube.com/watch?v=nqawLMoAyFI 
8. Speed of Light: https://www.youtube.com/watch?v=WHb8gEh7jA8

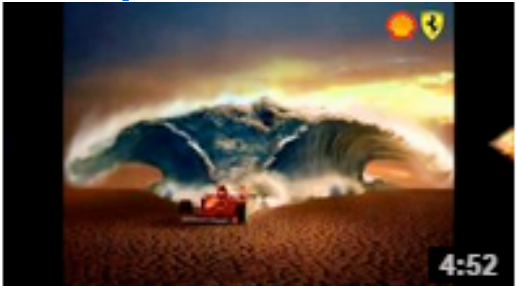

9. General Theory of Relativity: https://www.youtube.com/watch?v=8zgA0jar6X4

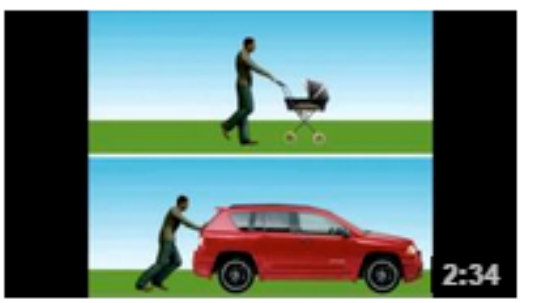

10. X-Rays: https://www.youtube.com/watch?v=muAmqX1Mr7I

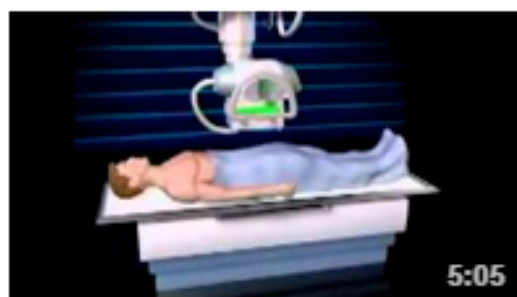

11. Gravitational Lens: https://www.youtube.com/watch?v=bhP-d-10KOw

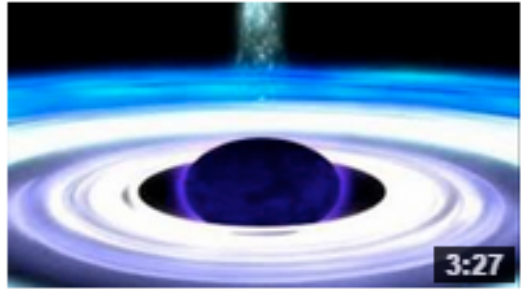

12. Models of Atom: https://www.youtube.com/watch?v=lO0gpJrOvBY

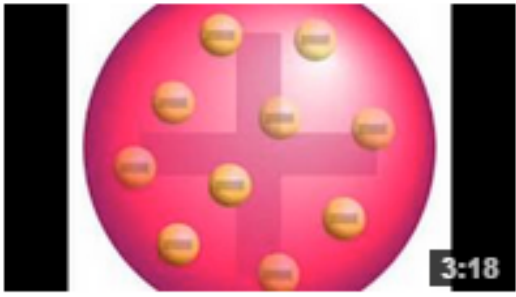

13. Heisenberg Uncertainty Principle:

https://www.youtube.com/watch?v=YX3Qc2ACKHA 


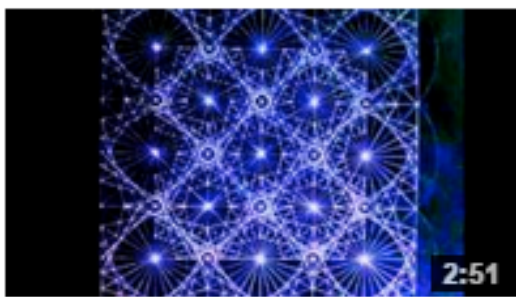

14. Special Relativity: https://www.youtube.com/watch?v=uxLZ6SxSsK0

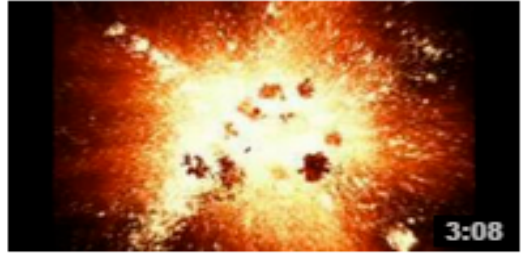

15. Compton Scattering: https://www.youtube.com/watch?v=oaKdCcsJw0o

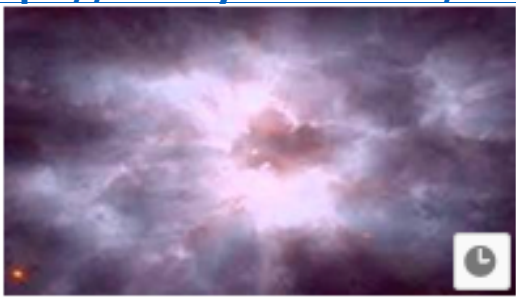

16. Black-Body Radiation: https://www.youtube.com/watch?v=8XtHg4xg2hw

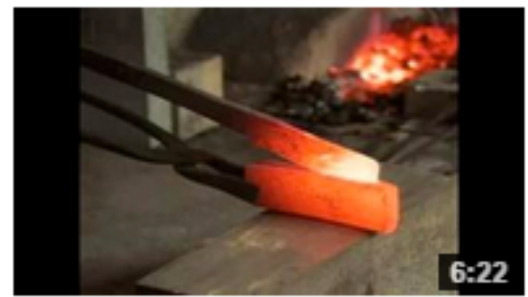

17. de Broglie Wavelength: https://www.youtube.com/watch?v=_hRet9mxtgI

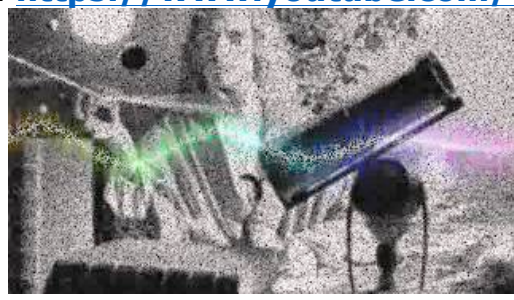

The researcher write down each pre-service teachers' view after application. According to participant:

1. The Digital Storytelling can be used for Distance Education activities (13 participant),

2. The use of Digital Storytelling on YouTube helped their learning(13 participant)

3. Digital Storytelling served as a learning aid (10 participant)

4. Using the Digital Storytelling as a distance education tool will be efficacious (13 participant)

5. Digital Storytelling allowed them more creativity in designing projects and assignments(10 participant).

\section{DISCUSSION}

It has become a necessity of information age to raise generations that have technology literacy and use technology effectively. In addition to enriching teaching new contents, 
the use of technology can be used to arouse interest and improve motivation (Sen, 2001). Nonetheless, along with raising individuals who have skills to use technology effectively, organized study materials for individuals should be produced as well. These may include videos, online learning environments, distance education tools and interactive technologic tools. What is more, it is a must that methods that consider individuals' technology literacy, interest, needs and motivations should be employed. Digital storytelling may be one of these methods to fulfil the need. Indeed, Hathorn (2005) indicated that creating digital stories increases learner's motivation and appears to enable individuals to gain hands-on experience. Whereas Tsou, Wang and Tzeng (2006) pointed out that digital storytelling achievement and interest, Dogan and Robin (2008) denoted that digital storytelling increases learner' motivation and engagement. In addition, Sadik (2008) emphasized that the employment of digital storytelling fosters learning course content and improves technology use, collaboration and communication skills.

Some researchers highlighted that physics subjects are difficult to learn and individuals have difficulty comprehending abstract concepts. In particular, subjects such as photoelectric effect, general creativity, blackbody radiation, Compton scattering that comprise abstract concepts are highly baffling for the learners. It is quite important to develop and use teaching activities that can prompts learner's visuals ideational perception in the process of teaching such concepts (Tas, Kose and Cepni, 2006). Producing digital stories about these subjects and enabling patterns, videos, music and animation that associate these subjects with real life to the learners will provide significant opportunities. To illustrate, individuals generally have difficulty in perceiving expressions of such concepts as curving space-time by mass, how the untouched objects manipulate the space-time, and how they show different movements like this, warping direction of the light by gravity and how this situation independent with characteristic of light, and how there is difference curve effect between stagnant and rotating celestial bodies. Yet in digital stories about this subject given on the link "General Relativity: https://www.youtube.com/watch?v=PIEmTnb90IE", how mass curve the space-time, how light is warped its direction by effect of the gravity, how curving of the stagnant and rotating celestial bodies to space time differ each other's is explained effectively along with music, audio and animation. This may enable individuals to easily figure out subjects that are difficult to learn. Not only with this digital story but also other given digital stories in this study can provide the best understandings to students about modern physics concepts.

When we regard students' achievement and interest in physics lesson in particular and their views on physics in general, it seems that digital storytelling as a distance education tool may bring out remarkable contributions somewhat. Indeed, view rates of 17 videos shared in Youtube channel may be an indication of this assumption. Similarly, as stated by Blas, Garzotto, Paolini and Sabiescu (2009) digital storytelling allows the students to gain interest in subject matters that mostly seem dull. Moreover, digital components may make the subject more enthralling.

\section{CONCLUSIONS}

Since today individuals have technologic devices such as smart phones, computers and internet, the use of digital storytelling as a distance education tool and publishing these stories may lead to considerable contributions. Anyone who feels like researching or exploring subject in physics can get through digital stories simply via internet access without the need to be present in teaching-instruction environment independent from time and space. Digital stories with high quality of teaching and learning traits may allow individuals to satisfy their curiosity about subjects. Therefore, it demonstrates that digital stories could be used as distance education tool in physics instruction.

As a result, teaching-instruction should not be any longer regarded as an activity applied merely in classroom. By employing today's technologies, individuals can attain knowledge 
anywhere and anytime they require. The knowledge may be in various forms such as text, audio, visual and their combination.

In sum, considering the importance of physics in real life, physics is one of the foremost disciplines that individuals need. However, subjects of physics should be attracting, clear and comprehensible. For this purpose, knowledge about physics subjects should appeal to multiple senses and should be available to individuals anytime and anywhere. Digital storytelling, consisting of audio-visual-music-animation and shared online, is one of the methods that can meet this need. Hence, the use of digital storytelling as a distance education tool in physics instruction bears great significance when it is considered that everyone will be able to reach digital stories without any restriction of space and time if digital stories are shared online.

\section{BIODATA and CONTACT ADDRESSES of the AUTHORS}

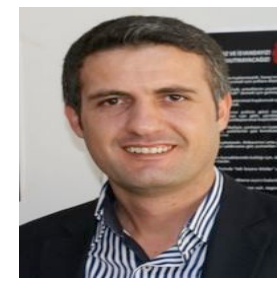

Nihat KOTLUK was born in Van, Turkey, in 1986. He graduated from Yuzuncu Yil University, Faculty of Education, Department of Physics Education in 2008. In 2012, he received his Master of Science in Physics Education, University of Yuzuncu Yil. He has been studying at Department of Curriculum and Instruction, Faculty of Education at Yuzuncu Yil University as a Doctorate Student, also working as Physics Teacher at High School in Van, Turkey. He has interest in the study of curriculum and instruction, teaching learning process, STEM education, teacher education, educational technology and distance education.

\section{Nihat KOTLUK}

Yuzuncu Yil University, Faculty of Education

Department of Curriculum and Instruction

65080 Zeve Campus, Van, TURKEY.

Phone: +905419087196

Fax: +904322141499

Email: nihatkotluk@gmail.com

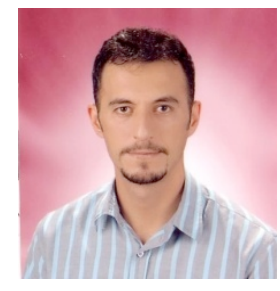

Assoc. Prof. Dr. Serhat KOCAKAYA was born in Diyarbakır at 1978 and graduated Department of physics faculty of Education, at Dicle University at 2000, Master of Science 2004 Dicle University institute of Science and phd. 2008 at Dicle University institute of science. He worked at the Department of Physics Education, Faculty of Education, at Dicle University, between 2005-2009. He is working at the Department of Physics Education, Faculty of Education, at Yuzuncu Yil University, since 2010. He has interest in the study of Physics Education, STEM education, and distance education.

Assoc. Prof. Dr. Serhat KOCAKAYA

Yuzuncu Yil University, Faculty of Education, Department of Physics education, Faculty of Education, 65080 Zeve Campus/Van, TURKEY

Tel/Fax: $04322251024 / 04322251038$

E-mail: skocakaya@gmail.com

\section{REFERENCES}

Alakoc, Z. (2003). Technological modern teaching approaches in mathematics teaching. The Turkish Online Journal of Educational Technology-TOJET 2.(1) 
Banaszewski, T. M. (2005). Digital storytelling: Supporting digital literacy in grades 4-12. Thesis, Georgia Institute of Technology.

Blas, N. D., Garzotto, F., Paolini, P. \& Sabiescu, A. (2009). Digital storytelling as a wholeclass learning activity: Lessons from a three-years Project. (Eds. I. A. Iurgel, N. Zagalo \& P. Petta). Interactive Storytelling: The Second Joint International Conference on Interactive Digital Storytelling, Guimarães, Portugal

Bulun, M., Gulnar, B. \& Guran, S. (2004). Mobile technology in education. The Turkish Online Journal of Educational Technology-TOJET 3. (2).

Chung, S. K. (2007). Art education technology: Digital storytelling. Art Education, 60 (2), 17-22

Coutinho, C. (2010). Storytelling as a strategy for integrating technologies into the curriculum: An empirical study with post-graduate teachers. In D. Gibson \& B. Dodge (Eds.), Proceedings of Society for Information Technology \& Teacher Education International Conference 2010. Chesapeake, VA: AACE.

Dogan, B. \& Robin, B. R. (2008). Implementation of digital storytelling in the classroom by teachers trained in a digital storytelling workshop. http://www.northamerican.edu (accessed May 20, 2014).

Dreon, O., Kerper, R. M. \&Landis, J. (2011). Digital Storytelling: A tool for teaching and learning in the Youtube Generation. Middle School Journey, 5 (42), 4-9.

Dupain, M. \& Maguire, L. (2005). Digital storybook projects 101: How to create and implement digital storytelling into your curriculum. 21st Annual Conference on DistanceTeachingandLearning.http://www.uwex.edu/disted/conference/resource_librar y/proceedings/05_2014.pdf (accessed June 6, 2014).

Garcia, P. A. \& Rossiter, M. (2010). Digital storytelling as narrative pedagogy. D. Gibson ve B. Dodge (Ed.), Proceedings of Society for Information Technology \& Teacher Education International Conference 2010 (s. 1091- 1097). Chesapeake, VA: AACE.

Garrety, C. M. (2008). Digital Storytelling: An emerging tool for student and teacher learning, Doktorate thesis, Iowa State University, Ames, Iowa

Gunduz, S. \& Odabasi, F. (2004). Importance of instructional technologies and material development course at pre-service teacher education in information age. The Turkish Online Journal of Educational Technology-TOJET 3. (7)

Hathorn, P. (2005). Using digital storytelling as a literacy tool for the inner city middle school youth. The Charter Schools Resource Journal, 1 (1), 32-38.

Jakes, D.S. \& Brennan, J. (2005). Capturing stories, capturing lives: An Introduction to digital storytelling. http://bookstoread.com/etp/earle.pdf (accessed September 20, 2014).

Kahraman, 0. (2013). The effect of using teaching materials prepared by digital storytelling method at engagement phase of learning cycle on physics course achievement and motivation level. Ph.D Thesis. Balikesir University, Institute of Science Education Balikesir, Turkey.

Kajder, S. B. ve Swenson, J.A. (2004). Digital Images in the Language Arts Classroom [Electronic version]. Learning and Leading with Technology, 31(8), 18-19. 
Karakoyun, F. (2014). Examining the views of elementary school students and preservice teachers about digital storytelling activities in online environment. Ph.D Thesis. Anadolu University, Institute of Educational Science, Eskişehir, Turkey.

Lambert, J. (2010). Digital storytelling cookbook and traveling companion. Berkeley, CA: Digital Diner Press

Nguyen, A. T. (2011). Negotiations and challenges in creating a digital story: The experience of graduate students. Dissertation (Ed. D.), University of Houston

Porter, B. (2004). Digitales: The art of telling digital stories. USA: Bernajean Porter Consulting.

Reiner, M. (2009). Sensory Cues, Visualization and Physics Learning. International Journal of Science Education,31(3), 343-364

Robin, B. (2006). The educational uses of digital storytelling. In C. Crawford et al. (Eds.), Proceedings of Society for Information Technology \& Teacher Education International Conference, Chesapeake, VA: AACE.

Robin, B. (2008). The effective uses of digital storytelling as a teaching and learning tool, Handbook of research on teaching literacy through the communicative and visual arts New York. Lawrence Erlbaum Associates

Robin, B. \& Pierson, M. (2005). A multilevel approach to using digital storytelling in the classroom. In C. Crawford et al. (Eds.), Proceedings of Society for Information Technology \& Teacher Education International Conference, Chesapeake, VA: AACE.

Sadik, A. (2008). Digital storytelling: A meaningful technology-integrated approach for engaged student learning. Educational Technology Research and Development, 56(4), 487-506.

Sen, A.I..(2001). New approaches in physics education supported with computers. Gazi Eğitim Fakültesi Dergisi 21, (3). 61-71.

Simsek, H., \& Yildirim, A. (2011). Qualitative research methods for social sciences. Seckin Yayıncılık, Ankara.

Standley, M. (2003). Digital Storytelling: Using new technology and the power of stories to help our students learn-and teach. cable in the classroom.

http://www.mediachalk.com/DigitalStorytellingAlaska.pdf (accessed September 9, 2014).

Tas, E., Kose, S. \& Cepni, S.(2006). The effects of computer-assisted instruction material on understanding photosynthesiss Subject. International Journal of Environmental and Science Education, 1 (2), 163 - 171.

Tsou, W., Wang, W. \& Tzeng, Y. (2006). Applying a multimedia storytelling website in foreign language learning. Computers and Education, 47, 17-28.

Wang, S. \& Zhan, H. (2010). Enhancing teaching and learning with digital storytelling. International Journal of Information and Communication Technology Education (IJICTE), 6 (2), 76-87.

Yang, Y. T. C. \& Wu, W. C. I. (2012). Digital storytelling for enhancing student academic achievement, critical thinking, and learning motivation: A year-long experimental study. Computers \& Education, 59 (2), 339-352 